\title{
Fenologia reprodutiva e caracterização físico-química de abacateiros em Carmo da Cachoeira, Minas Gerais ${ }^{1}$
}

\author{
Fábio Oseias dos Reis Silva 2 , José Darlan Ramos ${ }^{3}$, Marcelo Caetano de Oliveira ${ }^{4}$, \\ José Carlos Moraes Rufini ${ }^{5}$, Patrícia de Siqueira Ramos 6
}

\section{RESUMO}

O abacateiro é cultivado em algumas regiões tropicais e subtropicais. Seus frutos podem ser aproveitados de várias formas, utilizados ao natural ou na indústria de cosméticos, além da possibilidade de uso de seu óleo como fonte alternativa de biocombustível. Assim, o objetivo deste trabalho foi avaliar as características fenológicas e físicoquímicas das variedades de abacateiros, visando a identificar variedades promissoras para Carmo da Cachoeira, Minas Gerais. O trabalho foi realizado durante os ciclos reprodutivos de 2008/2009 e 2009/2010. As variedades avaliadas foram: 'Breda', 'Fortuna', 'Fuerte', 'Hass', 'Margarida', 'Ouro Verde' e 'Quintal'. Foram avaliadas as características fenológicas (início das brotações, início da floração, plena floração, final de floração e período de duração da floração, início da frutificação, início e final da colheita e tempo de colheita). As análises físicas e químicas incluíram: diâmetros longitudinal e transversal, percentagens de polpa, casca e caroço em relação à massa total, composição centesimal (lipídeos e umidade). Para as avaliações fenológicas, foram marcadas ao acaso seis plantas de cada variedade. Para as análises físico-químicas, utilizou-se o delineamento inteiramente casualizado (DIC), com sete tratamentos (variedades), seis repetições, com seis frutos por parcela. Concluiu-se que, em relação à fenologia, todas as variedades floresceram de maneira satisfatória na região estudada. As variedades 'Fortuna', 'Quintal' destacaram-se para o consumo in natura, para o mercado interno, por apresentarem características desejáveis para o consumidor brasileiro. As variedades 'Hass' e 'Fuerte' apresentaram os melhores resultados quanto ao teor de óleo na polpa, destacando-se como as mais promissoras para a extração de óleo.

Palavras-chave: Persea sp., lipídeos, variedades, estádios fenológicos.

\section{ABSTRACT \\ Reproductive phenology and physicochemical characterization of avocado varieties in Carmo da Cachoeira, Minas Gerais, Brazil}

The avocado tree is cultivated in tropical and subtropical regions. Avocado fruits can be used in a variety of ways; fresh fruit consumption, in the cosmetic industry and the possibility of using the oil as an alternative source of biofuel. Thus, the objective of this work was to evaluate the phenological and physicochemical characteristics of avocado varieties, aiming .to identify the promising varieties from Carmo da Cachoeira, Minas Gerais. The work was carried out during the reproductive cycles of 2008/2009 and 2009/2010. The evaluated varieties were: 'Breda', 'Fortuna', 'Fuerte', 'Hass', 'Margarida', 'Ouro Verde' and 'Quintal'. The phenological characteristics (early sprouting, early flowering, full

\footnotetext{
Recebido para publicação em 18/09/2012 e aprovado em 26/06/2013.

${ }^{1}$ Este trabalho é parte da dissertação de mestrado do primeiro autor. Fonte financiadora: FAPEMIG, CAPES e CNPq.

2Engenheiro-Agrônomo, Mestre. Departamento de Agricultura, Universidade Federal de Lavras, Caixa Postal 3037, 37200-000, Lavras, Minas Gerais, Brasil. foseias@yahoo.com.br (autor para correspondência).

${ }^{3}$ Engenheiro-Agrônomo, Doutor. Departamento de Agricultura, Universidade Federal de Lavras, Caixa Postal 3037, 37200-000, Lavras, Minas Gerais, Brasil. darlan@ dag.ufla.br ${ }^{4}$ Engenheiro-Agrônomo, Ph.D. Departamento de Agricultura, Universidade Federal de Lavras, Caixa Postal 3037, 37200-000, Lavras, Minas Gerais, Brasil. caetanocaldas@ hotmail.com

${ }^{5}$ Engenheiro-Agrônomo, Doutor. Universidade Federal de São João del-Rei, Campus Sete Lagoas, Rodovia MG 424, Km 47, Caixa Postal 56, 35701-970, Sete Lagoas, Minas Gerais, Brasil.rufini@ufsj.edu.br

${ }^{6}$ Bacharela em Ciências da Computação, Doutora. Instituto de Ciências Exatas, Universidade Federal de Alfenas, Rua Gabriel da Silva Monteiro, 700, Centro, 37130-000, Alfenas, Minas Gerais, Brasil. siqueirapaty@gmail.com
} 
flowering and duration of flowering, early fructification, early and late harvest and harvest time) were evaluated. The physical and chemical characteristics included longitudinal and transverse diameters, percentage of pulp, peel and seed against the total mass and centesimal composition (lipids and moisture). For the phenological characteristics, six plants of each variety were marked randomly. For the physicochemical characteristics, we used a completely randomized design (CRD) with seven treatments (varieties), six replicates with six fruit per plot. In relation to phenology, all the varieties flowered in a satisfactory manner in the investigated region. The varieties 'Fortuna' and 'Quintal' stood out for the fresh consumption for the domestic market for presenting the desirable characteristics for the Brazilian consumers. The varieties 'Hass' and 'Fuerte' presented the best results for oil content in the pulp, standing out as the most promising for oil extraction.

Key words: Persea sp., lipids, varieties, phenological stages.

\section{INTRODUÇÃO}

O Abacateiro (Persea americana Mill.) é cultivado em vários locais no mundo, principalmente em regiões tropicais e subtropicais do México, África do Sul, Israel, Havaí, Taiti, Austrália e Estados Unidos (Teixeira, 1991). O México é o maior produtor mundial, com 1.124.565 toneladas, seguido do Chile, Indonésia, República Dominicana e Colômbia. O Brasil ocupa a sexta posição, com 166 mil toneladas, em 9,45 mil hectares, com sua produção concentrada principalmente na região sudeste, onde o Estado de São Paulo apresenta aproximadamente $35 \%$ da área cultivada e $41 \%$ da produção nacional, seguido de Minas Gerais, com 23\% da área e 16\% da produção (Agrianual, 2011).

$\mathrm{O}$ abacate pode ser utilizado de diferentes formas, como fruta fresca, em pratos típicos e, além disso, da polpa extrai-se o óleo, que é muito utilizado, na indústria de cosméticos, em cremes, loções e outros produtos de beleza (Falcão et al., 2001). Além das formas de utilizações citadas, o abacate pode ser uma nova fonte alternativa de biocombustível (Menezes, 2009).

Dependendo das localidades de implantação da cultura e das variedades cultivadas, pode-se ofertar ao mercado o produto em várias épocas do ano. Isso ocorre por que as plantas apresentam diferentes respostas fenológicas, conforme as condições climáticas e altitude do local de cultivo (Duarte Filho et al., 2008). Na região de Campinas, por exemplo, a época de colheita das variedades 'Fortuna' e 'Quintal' estende-se de Maio a Junho (Tango et al., 2004); já, em Goiás, a época de colheita da variedade 'Fortuna' ocorre de Março a Julho, enquanto os frutos da variedade 'Quintal' são colhidos de Março a Agosto (Ramos et al., 2008).

Outras pesquisas mostram que o teor de óleo do fruto pode variar em função da fenologia. Nos estudos realizados por Tango et al., (2004), observaram-se variações de 5 a 30\% nos teores de lipídeos da polpa. Já, nas pesquisas realizadas por Massafera et al., (2010), os resultados foram contrastantes, em relação aos dados encontrados por Tango et al., (2004) para as mesmas variedades estudadas. Além das características fenológicas e químicas, podem ocorrer variações no conteúdo da massa dos frutos, em diferentes regiões (Tango et al. 2004; Criziel et al., 2008).

As variações fenológicas, principalmente a data de floração, são de grande interesse para o cultivo do abacateiro, visto que essa frutífera apresenta dicogamia protogínica, ou seja, o órgão feminino está sempre receptivo antes do órgão masculino. Dessa forma, recomendase que, no local de plantio se intercalem variedades pertencentes a grupos diferentes (Falcão et al., 2001).

Diante do exposto, o objetivo deste trabalho foi avaliar as características fenológicas e físico-químicas das variedades de abacateiros, visando a identificar variedades promissoras para Carmo da Cachoeira, Minas Gerais.

\section{MATERIAL E MÉTODOS}

A coleta de dados no campo foi efetuada em propriedade particular, situada às margens da BR 381, km 727, no município de Carmo da Cachoeira no sul do Estado de Minas Gerais, situada a 21 ${ }^{\circ} 29^{\prime} 55^{\prime}$ 'Sul e 4512'47' Oeste, com altitude média de 987 metros. O clima da região é classificado como Cwb, clima mesotérmico ou tropical de altitude, com inverno seco e verão chuvoso e temperaturas amenas, segundo a classificação de Köeppen. A classe de solo predominante na região do estudo é o Latossolo Vermelho-Amarelo distrófico.

As variedades utilizadas nas avaliações foram: 'Breda', 'Fortuna', 'Fuerte', 'Hass', 'Margarida', 'Ouro Verde' e 'Quintal'. As plantas pertencem a um pomar de abacateiros com 15 anos de idade, em espaçamento 10 x 10 m. Para a caracterização fenológica, as árvores foram marcadas e avaliadas nas safras de 2008/09 e 2009/10. 
As características estudadas foram: início da emissão das brotações, início da floração (5\% flores abertas), plena floração (70\% das flores abertas) e final de floração ( $95 \%$ ou mais das flores abertas), período de duração do florescimento, início da frutificação (5\% de frutos fixados), início e final da colheita e tempo de colheita.

Para se calcular as percentagens, procedeu-se da seguinte forma: foram marcados 12 ramos aleatórios, distribuídos em toda a circunferência, na parte mediana da planta, e identificados com auxílio de fitas coloridas, dos quais se contou o número total de flores e frutos e, posteriormente, o número de flores abertas e frutos fixados, a cada três dias. No final, determinaram-se os períodos de florescimento, frutificação e colheita.

Foram marcadas ao acaso seis plantas de cada variedade, totalizando 42 plantas.

À medida que se observou redução da coloração brilhante dos frutos e eles passaram a ter coloração opaca, foi feita a colheita. Foram colhidos frutos ao acaso, os quais foram pré-selecionados, lavados com água, sem aplicação de produtos fitossanitários e, posteriormente, foram levados ao Laboratório de Pós-colheita de Frutos e Hortaliças, da Universidade Federal de Lavras - MG, onde foram feitas as análises físicas e químicas. Determinaramse os diâmetros longitudinal e transversal, utilizando-se um paquímetro de metal, a massa, as percentagens de polpa, casca e caroço, em relação à massa total dos frutos (determinados em balança de precisão), além do teor de umidade e de lipídeos, determinados segundo a metodologia descrita pela AOAC (1997).

Nas análises físicas e químicas, o delineamento experimental utilizado foi o inteiramente casualizado (DIC), com sete tratamentos (variedades), três repetições (plantas), seis frutos por parcela. Os dados foram submetidos à análise de variância e teste de Tukey, com significância igual ou inferior a 5\% de probabilidade, no programa estatístico Sisvar (Ferreira, 2000), sendo utilizado o modelo estatítico $\mathrm{Y}_{\mathrm{ij}}=\mu+\mathrm{t}_{\mathrm{i}}+\mathrm{e}_{\mathrm{ij}}$, em que: $\mathrm{Y}_{\mathrm{ij}}$ : observação feita na parcela para o tratamento i na repetição $\mathrm{j} ; \mu$ : constante inerente a toda parcela; $t_{\mathrm{i}}$ efeito do tratamento; $\mathrm{e}_{\mathrm{ij}}$ : erro experimental na parcela $\mathrm{i}, \mathrm{j}$.

\section{RESULTADOS E DISCUSSÃO}

De acordo com os resultados obtidos, verifica-se que a emissão das brotações (EB), nos dois ciclos avaliados, ocorreu, primeiramente, em 'Fuerte' e 'Hass', e, tardiamente, em 'Margarida', 'Ouro Verde'e 'Quintal' nos ciclos 2008/2009 e 2009/2010. No primeiro ciclo, a emissão das brotações ocorreu em agosto e terminou em outubro. Para a segunda safra, a emissão das brotações da maioria das variedades concentrou-se no mês de agosto (Tabela 1).
Pela Tabela 1, observa-se que o início da emissão da brotação em 'Breda', 'Fortuna', 'Ouro Verde' e 'Quintal' ocorreu simultaneamente ao início de frutificação (ciclo 2008/2009). O mesmo ocorreu para 'Ouro Verde' no ciclo 2009/2010. Respostas semelhantes também foram observadas por Falcão et al., (2001), em estudo com nove variedades de abacateiros na Amazônia Central. Segundo Fachinello (2011), a presença de frutos em quantidades elevadas concorre com a indução floral, principalmente pela relação que existe com a síntese e translocação de giberelinas das sementes dos frutos e nos ápices de crescimento.

O início do florescimento (IF) de 'Breda', 'Fuerte', 'Hass' e 'Quintal' ocorreu no mês de agosto, enquanto 'Fortuna', 'Margarida' e 'Ouro Verde' iniciaram a floração em setembro, como se observou no ciclo 2008/2009 (Tabela 1).

O fim do florescimento (FF) da 'Quintal' ocorreu no mês de Setembro. As variedades 'Breda', 'Fortuna', 'Fuerte', 'Hass' e 'Margarida' finalizaram a floração no mês de outubro, enquanto o fim da floração da 'Ouro Verde' ocorreu em novembro, no ciclo 2008/2009 (Tabela 1).

Já para o ciclo 2009/2010, observaram-se variações nas épocas de início e de término do florescimento, em relação aos da safra anterior. O início de florescimento para 'Breda', 'Fortuna', 'Fuerte', 'Hass', 'Margarida' e 'Quintal' ocorreu no mês de agosto, enquanto o florescimento da 'Ouro Verde' ocorreu no mês de setembro. O fim do florescimento para 'Fuerte', 'Hass' e 'Quintal' ocorreu no mês de setembro, enquanto o florescimento de 'Breda', 'Fortuna', 'Margarida' e 'Ouro Verde' finalizou-se em outubro (Tabela 1). De maneira geral, observa-se que houve um atraso de dois meses no florescimento de todas as variedades, exceto a 'Ouro Verde' que floresceu com um mês de atraso na safra 2009/2010 em relação a safra 2008/2009.

As variações nas épocas dos florescimentos podem ter ocorrido possivelmente por causa das oscilações de temperaturas (Figura 1) entre os meses em que provavelmente ocorreu a indução floral (Março a Setembro), nos ciclos 2008/2009 e 2009/2010. Segundo Buttrose \& Alexander (1978), temperaturas $\leq 15^{\circ} \mathrm{C}$ e fotoperíodo $\leq 10$ $\mathrm{h}$, durante quatro semanas, são suficientes para induzir a gema vegetativa a converter-se em florífera, em abacateiros 'Fuerte' e Hass'. Resultados semelhantes foram obtidos por Falcão et al. (2001), que observaram variações nas fases reprodutivas das plantas avaliadas.

O período de florescimento (IF-FF) durou em média 48 dias, para os dois ciclos. No primeiro ciclo, o menor período registrado foi para 'Fortuna' e o maior foi para 'Fuerte'. No segundo ciclo, 'Breda' apresentou o maior período, enquanto o menor período ocorreu para 'Ouro Verde', como pode ser observado na Tabela 1 . 
O período de florescimento é um evento que influencia a produtividade. Se as condições edafoclimáticas, fitossanitárias e aquelas relacionadas com a polinização não estiverem adequadas, a frutificação poderá ficar comprometida. Além disso, o abacateiro apresenta o fenômeno chamado dicogamia protogínica; portanto, para que ocorra a polinização e, consequentemente, a frutificação, existe a necessidade da presença de abacateiros de diferentes grupos florais (A e B), cultivares que floresçam na mesma época, para assegurar uma polinização mais eficiente das flores (Koller, 2002). De forma geral, pode-se observar que houve uma sincronia, uma sobreposição dos períodos de florescimento das variedades dos diferentes grupos florais (Tabela 1), favorecendo, sobretudo a polinização dos abacateiros.

Nos dois ciclos de produção, o início da frutificação aconteceu, principalmente, no mês de Setembro, para as variedades estudadas (Tabela 1). Para a variedade 'Quin-

Tabela 1. Avaliação fenológica das plantas de abacateiros (2008/2009; 2009/2010), no município de Carmo da Cachoeira- MG

\begin{tabular}{|c|c|c|c|c|c|c|c|c|c|}
\hline \multirow{2}{*}{ Var.** } & EB & IF & PF & FF & IF-FF & IFR & IC & FC & IC-FC \\
\hline & \multicolumn{9}{|c|}{$2008 / 2009$} \\
\hline $\operatorname{Breda}\left(\mathrm{A}^{*}\right)$ & 03/09 & $19 / 08$ & $23 / 09$ & $25 / 10$ & 52 & $26 / 09$ & $29 / 09$ & $19 / 10$ & 20 \\
\hline Fortuna (A) & 06/09 & 06/09 & $25 / 10$ & $15 / 10$ & 39 & $28 / 09$ & $29 / 07$ & $17 / 08$ & 19 \\
\hline Fuerte (B) & $22 / 08$ & $22 / 08$ & $01 / 10$ & $18 / 10$ & 56 & $25 / 09$ & $25 / 09$ & $14 / 10$ & 19 \\
\hline Hass (A) & $23 / 08$ & $23 / 08$ & $09 / 10$ & $18 / 10$ & 55 & $25 / 09$ & $25 / 09$ & $15 / 10$ & 20 \\
\hline Margar. (B) & $04 / 10$ & 04/09 & $25 / 09$ & $21 / 10$ & 47 & $22 / 09$ & $21 / 10$ & $13 / 11$ & 22 \\
\hline O.Verde (A) & $25 / 09$ & $29 / 09$ & $21 / 10$ & $10 / 11$ & 42 & $19 / 09$ & $29 / 08$ & $15 / 09$ & 17 \\
\hline \multirow[t]{2}{*}{ Quintal (B) } & $15 / 09$ & 09/08 & 04/09 & $26 / 09$ & 47 & $02 / 09$ & $15 / 07$ & $06 / 08$ & 21 \\
\hline & \multicolumn{9}{|c|}{$2009 / 2010$} \\
\hline $\operatorname{Breda}\left(\mathrm{A}^{*}\right)$ & $21 / 08$ & $21 / 08$ & $14 / 09$ & $15 / 10$ & 54 & $18 / 09$ & $20 / 09$ & $09 / 10$ & 19 \\
\hline Fortuna (B) & $24 / 08$ & $24 / 08$ & $15 / 10$ & $05 / 10$ & 41 & $18 / 09$ & $20 / 07$ & 08/08 & 19 \\
\hline Fuerte (B) & $10 / 08$ & $10 / 08$ & $18 / 09$ & $30 / 09$ & 50 & $15 / 09$ & $10 / 09$ & $01 / 10$ & 21 \\
\hline Hass (A) & $10 / 08$ & $10 / 08$ & $18 / 09$ & $30 / 09$ & 50 & $15 / 09$ & $10 / 09$ & $06 / 10$ & 26 \\
\hline Margar. (B) & $24 / 08$ & $24 / 08$ & $15 / 09$ & $10 / 10$ & 46 & $10 / 09$ & $08 / 10$ & $04 / 11$ & 26 \\
\hline O.Verde (A) & $15 / 09$ & $20 / 09$ & $10 / 10$ & $30 / 10$ & 40 & $10 / 09$ & $10 / 08$ & $28 / 08$ & 18 \\
\hline Quintal (B) & 05/09 & 01/08 & $24 / 08$ & $15 / 09$ & 45 & $20 / 08$ & 05/07 & $23 / 07$ & 18 \\
\hline
\end{tabular}

IB: Início da Brotação; IF: Início da Floração (5\% flores abertas); PF: Plena Floração (+ 70\% flores abertas); FF: Final de Floração (95\% ou mais das flores abertas); IF-FF: Duração do florescimento; IFR: Início da Frutificação; IC: Início da Colheita; FC: Final da Colheita; ICFC: Tempo de Colheita.

*Grupo Floral que pertence a variedade estudada; **Var.: variedade; Marg.: Margarida; O.Verde: Ouro Verde.



Figura 1. Médias mensais da temperatura máxima e mínima, precipitação entre os meses de janeiro de 2008 a novembro de 2010 em Carmo da Cachoeira - MG.

Rev. Ceres, Viçosa, v. 61, n.1, p. 105-111, jan/fev, 2014 
tal', a frutificação aconteceu precocemente, enquanto as variedades 'Breda' e 'Fortuna' apresentaram o início da frutificação tardio, em relação ao das outras variedades (ciclos 2008/2009 e 2009/2010).

Com relação ao início da colheita, nos dois ciclos, a variedade 'Quintal' foi a mais precoce e 'Margarida' a mais tardia, sendo colhidas em Julho e Outubro, respectivamente (Tabela 1).

Para o final da colheita, pode-se observar que a variedade 'Quintal' foi a mais precoce; o fim da sua colheita ocorreu em Agosto, enquanto a variedade 'Margarida' mostrou-se a mais tardia, em comparação com as outras variedades, sendo colhida no mês de Novembro, tanto no primeiro ciclo, quanto no segundo (Tabela 1).

Nos dois ciclos de avaliação, o período de colheita estendeu-se entre os meses de julho e novembro, com duração média de aproximadamente 21 dias de colheita para cada variedade. $\mathrm{O}$ menor período de colheita ocorreu no primeiro ciclo de avaliação para a variedade 'Ouro Verde'; o maior período foi observado no segundo ciclo, com as variedades 'Hass' e 'Margarida' (Tabela 1). O longo período de colheita, de aproximadamente 5 meses, facilita a logística de toda a cadeia produtiva do abacateiro. $\mathrm{O}$ abacate é um fruto climatérico, apresentando altas taxas respiratórias e produção elevada de etileno, sendo altamente perecível em condições ambientais (Kader, 1992). Segundo Kluge et al. (2002), o principal fator que limita o transporte e o tempo de comercialização, e que deprecia a qualidade de pós- colheita da fruta é o amolecimento excessivo decorrente do amadurecimento.

Observa-se que na região em questão, de maneira geral, as variedades de abacateiros produziram no segundo semestre nos dois ciclos estudados. De acordo com o descrito por Genú et al. (1982), as variedades e Pollock (grupo floral B) e Simonds (grupo floral A) produzem respectivamente de janeiro a abril e fevereiro a abril. Já as variedades Waldin (grupo floral A) x Vitória (Grupo floral B) produzem de março a maio e de março a agosto respectivamente. Dentro desse contexto, essas variedades poderiam ser opções de cultivo em Carmo da Cachoeira, havendo, entretanto, a necessidade de estudos detalhados que possam comprovar o desenvolvimento e produtividade satisfatórios para a região.

De acordo com a Tabela 2, observa-se que 'Quintal' apresentou o maior diâmetro longitudinal enquanto 'Hass' e 'Fuerte' apresentaram os menores valores para a variável analisada. Para o diâmetro transversal (DT), 'Margarida', 'Fortuna' e 'Breda' foram superiores às demais, enquanto 'Hass' e 'Fuerte' apresentaram menores valores para a variável estudada. Esses resultados corroboram com Oliveira et al. (2013), quando avaliaram 13 variedades de abacateiros, em São Bento do Sapucaí, SP onde os dados obtidos são similares.
Em relação às massas dos frutos, 'Fortuna' e 'Quintal' apresentaram valores maiores que 'Fuerte' e 'Hass'. Em relação à polpa, 'Fortuna' e 'Quintal' destacaram-se com as maiores percentagens, enquanto 'Fuerte' e 'Hass' apresentaram os menores valores (Tabela 2).

A descrição das variáveis diâmetro e massa é de grande importância. Segundo Tango \& Turatti (1992), a polpa é a porção de maior interesse, pois nela se encontra a maior parte dos lipídeos. Sabe-se que mesmo apresentando altos valores de polpa, 'Fortuna' e 'Quintal' têm baixos valores para óleo (Tango et al., 2004), sugerindo que estas variedades são interessantes para o mercado nacional, visto que apresentam características que se aproximam das desejadas pelo consumidor brasileiro, como frutos grandes, com mais de 400 gramas, casca verde e formato piriforme (Camargo \& Manco, 2002).

Para a variável casca, 'Fuerte' e 'Hass' apresentaram as maiores percentagens, enquanto 'Fortuna' e 'Quintal' apresentaram os menores valores. A respeito da porção caroço, 'Fuerte' e 'Hass' apresentaram as maiores percentagens, enquanto 'Fortuna' e 'Quintal' apresentaram os menores valores (Tabela 2). Tango et al., (2004) mencionam que casca e caroço não são interessantes, pois, os teores de lipídeos presentes nestas porções são reduzidos. Dessa forma, percebe-se que 'Fuerte' e 'Hass' apresentam altos valores para as variáveis que limitam a extração de óleo; no entanto, estas variedades apresentam altas percentagens de óleo na polpa, que compensam os altos valores das variáveis indesejadas.

Verifica-se pela tabela 3 que as variedades 'Fuerte' e 'Hass' apresentaram maiores concentrações de teor lipídico na polpa do fruto, sendo 'Fortuna' e 'Margarida' as que apresentaram as menores concentrações. A variedade 'Fuerte' apresentou menor teor de água, seguida de 'Hass', enquanto 'Margarida' e 'Fortuna' apresentaram os maiores teores de água. Dessa forma, pode-se observar que existe um comportamento inverso entre o teor de umidade e o de lipídeos, confirmando os resultados en-

Tabela 3. Percentagens do teor de lipídeos e umidade presentes em cada uma das sete variedades de abacateiros no momento da colheita, em Carmo da Cachoeira-MG

\begin{tabular}{lcc}
\hline Cultivares & Lipídeos $(\%)$ & Umidade (\%) \\
\hline Fuerte & $24,0 \mathrm{a}$ & $59,70 \mathrm{a}$ \\
Hass & $20,9 \mathrm{~b}$ & $61,31 \mathrm{a}$ \\
Quintal & $13,6 \mathrm{c}$ & $73,19 \mathrm{~b}$ \\
Ouro Verde & 12,3 cd & $79,18 \mathrm{c}$ \\
Margarida & 11,9 ef & $80,90 \mathrm{~d}$ \\
Fortuna & $10,4 \quad$ f & $81,57 \mathrm{~d}$ \\
Breda & 12,2 cd & $77,57 \mathrm{c}$ \\
\hline CV(\%) & 18,02 & 1,57 \\
\hline
\end{tabular}

Médias seguidas da mesma letra na coluna não diferem entre si, pelo teste Tukey, a 5\% de probabilidade. 
contrados por Tango et al. (2004), que também verificaram alta correlação negativa entre o teor de umidade e o de lipídeo, nas polpas frescas de 24 variedades de abacateiro. Os resultados encontrados neste estudo estão de acordo com os de trabalho anteriormente realizado, em que 'Hass' e 'Fuerte' destacaram-se quanto à percentagem de lipídeos na polpa (Tango et al., 2004).

Segundo Tango et al. (2004), o elevado conteúdo de umidade na polpa fresca constitui a principal limitação para obtenção de óleo de abacate, afetando o rendimento de ex- tração e o custo de produção. A explicação está no fato de que a água ocasiona um impedimento ao contato entre o solvente extrator e o produto a ser extraído (Campos, 2009). Entretanto, apesar dessa limitação na extração de óleo da polpa de abacate, o cultivo do abacateiro tem grande potencial, considerando-se o rendimento de óleo por unidade de área (Canto et al., 1980). Neste trabalho, fica claro que as variedades 'Fuerte' e 'Hass' apresentam grande potencial para a extração de óleo, pois foram as que apresentaram maiores teores de lipídeos e mais baixos conteúdos de umidade.

Tabela 2. Dimensões dos frutos, proporções dos componentes: polpa, caroço e casca nos frutos de variedades de abacateiro no momento da colheita, em Carmo da Cachoeira-MG

\begin{tabular}{lcccccc}
\hline Variedade & DL $(\mathbf{c m})$ & DT $(\mathbf{c m})$ & Massa $(\mathbf{K g})$ & Polpa $(\%)$ & Casca $(\%)$ & Caroço $(\%)$ \\
\hline Breda & $9,2 \mathrm{~b}$ & $8,1 \mathrm{a}$ & $0,6 \mathrm{~b}$ & $69,1 \mathrm{bc}$ & $12,6 \mathrm{~b}$ & $17,5 \mathrm{bc}$ \\
Fortuna & $10,3 \mathrm{~b}$ & $8,2 \mathrm{a}$ & $0,9 \mathrm{a}$ & $78,6 \mathrm{a}$ & $8,8 \mathrm{ab}$ & $11,3 \mathrm{a}$ \\
Fuerte & $8,8 \mathrm{bc}$ & $6,8 \mathrm{c}$ & $0,2 \mathrm{c}$ & $62,6 \mathrm{c}$ & $17,6 \mathrm{c}$ & $18,7 \mathrm{c}$ \\
Hass & $7,6 \mathrm{c}$ & $5,7 \mathrm{c}$ & $0,2 \mathrm{c}$ & $59,9 \mathrm{~d}$ & $16,7 \mathrm{c}$ & $25,7 \mathrm{~d}$ \\
Margarida & $9,1 \mathrm{~b}$ & $8,9 \mathrm{a}$ & $0,6 \mathrm{~b}$ & $72,8 \mathrm{~b}$ & $10,5 \mathrm{ab}$ & $15,5 \mathrm{~b}$ \\
O. Verde* & $9,8 \mathrm{~b}$ & $7,6 \mathrm{bc}$ & $0,6 \mathrm{~b}$ & $68,2 \mathrm{c}$ & $11,9 \mathrm{~b}$ & $18,6 \mathrm{c}$ \\
Quintal & $12,3 \mathrm{a}$ & $7,9 \mathrm{~b}$ & $1,1 \mathrm{a}$ & $81,6 \mathrm{a}$ & $5,6 \mathrm{a}$ & $10,6 \mathrm{ab}$ \\
\hline CV $(\%)$ & 11,2 & 8,1 & 15,4 & 10,6 & 24,1 & 17,2 \\
\hline
\end{tabular}

Médias seguidas da mesma letra na coluna não diferem entre si, pelo teste Tukey, a 5\% de probabilidade.

* O. Verde: Ouro Verde; DL: diâmetro longitudinal; DT: diâmetro transversal.

\section{CONCLUSÕES}

Com relação à fenologia, todas as variedades avaliadas destacaram-se como promissoras para a região estudada, florescendo de maneira satisfatória.

As variedades 'Fortuna' e 'Quintal' destacaram-se para o consumo in natura, para o mercado interno, por apresentarem características desejadas pelo consumidor brasileiro. Entretanto, existe a necessidade de enfatizar que outras variedades podem ser de interesse, se o objetivo for a produção por longos períodos do ano.

As variedades 'Hass' e 'Fuerte' apresentaram os melhores resultados quanto ao teor de óleo na polpa, destacando-se como as mais promissoras para a extração de óleo.

\section{AGRADECIMENTOS}

Os autores agradecem ao Sr. José Alcides Bonella e ao Sr. Cláudio Eduardo Facci Júnior, pelas contribuições estruturais prestadas ao desenvolvimento do trabalho; à Coordenação de Aperfeiçoamento de Pessoal de Nível Superior (CAPES), ao Conselho Nacional de Desenvolvimento Científico e Tecnológico (CNPq) e à Fundação de Amparo à Pesquisa do Estado de Minas Gerais (FAPEMIG), pela concessão das bolsas aos estudantes envolvidos.

\section{REFERÊNCIAS}

Agrianual (2011) Anuário da agricultura brasileira. São Paulo, FNP Consultoria. $482 \mathrm{p}$.

AOAC - Association Of Official Analytical Chemists (1997) Official methods of analysis of the association of official analytical chemistry. 16 ${ }^{\mathrm{a}}$ ed. Washington, AOAC. 1018p.

Buttrose MS \& Alexander DM (1978) Promotion of floral initiation in 'Fuerte' avocado by low temperature and short daylength. Scientia Horticulturae, 8:213-219.

Camargo GF, Manco JR Participação do mercado de abacate no etsp da CEAGESP em 2002. Disponível em: <http://www.todafruta.com.br/ portal/icNoticiaAberta.asp?idNoticia $=6274>$. Acessado em: 13 de abril de 2013 .

Campos RA (2009) Otimização de método de extração de óleo presente em polpa de abacate. Dissertação de Mestrado. Universidade Estadual Paulista, Araraquara, 71p.

Canto WL, Santos LC \& Travaglini MME (1980) Óleo de abacate: extração, usos e seus mercados atuais no Brasil e na Europa. Campinas, ITAL. 144p. (Alimentos Processados, 11).

Criziel GR, Moura RS, Oliveira IR \& Mendonça CRB (2008) Características físicas e químicas de abacates das variedades Quintal e Hass. In: XVII Congresso de Iniciação Científica, X Encontro de Pós Graduação, Pelotas. Anais, UFPEL.

Duarte Filho J, Leonel S, Caproni CM \& Grossi RS (2008) Principais variedades de abacateiros. In: Leonel S \& Sampaio AC (Eds.) Abacate: aspectos técnicos da produção. São Paulo, Cultura Acadêmica. p.25-36.

Fachinello JC (2011) Fruticultura: fundamentos e práticas. Disponível em: http://www.cpact.embrapa.br/publicacoes/download/ livro/fruticultura_fundamentos_pratica/6.4.htm. Acessado em: 14 de agosto de 2011. 
Falcão MA, Paraluppi ND, Clement CR, Kerr WE \& Silva MF (2001) Fenologia e produtividade do abacate (Persea americana Mill.) na Amazônia Central. Acta Amazônica, 31:3-9.

Ferreira DF (2000) Análise estatística por meio do SISVAR (Sistema para Análise de Variância) para Windows versão 4.0. In: 45 Reunião Anual da Região Brasileira da Sociedade Internacional de Biometria, São Carlos. Anais, UFSCar. p.255-258.

Genú PJC, Pinto ACQ, Ferreira FR (1992) Banco ativo de germoplama de abacateiro. Relatório anual do Centro de Pesquisa Agropecuária dos Cerrados 19801- 1981, Planaltina, DF. p. $121-123$.

Kader AA (1992) Postharvest technology of horticultural crops. Okland, University of California. 292p.

Kluge RA, Jacomino AP, Ramon MO \& Brackmann A (2002) Inibição do amadurecimento de abacate com 1metilciclopropeno. Pesquisa Agropecuária Brasileira, 37:895901.

Koller OC (2002) Abacate: produção de mudas, instalação e manejo de pomares, colheita e pós-colheita. Porto Alegre, Cinco Continentes. $149 \mathrm{p}$.

Massafera G, Costa TMB \& Oliveira JED (2010) Composição de ácidos graxos do óleo do mesocarpo e da semente de cultivares de abacate (Persea americana, Mill) da região de Ribeirão Preto, SP. Revista Alimentos e Nutrição, 21:325-331.
Menezes ML (2009) Biodiesel de abacate. Disponível em: <http:/ /agencia.fapesp.br/10601>. Acessado em: 4 de julho de 2011.

Oliveira MC, Pio R, Ramos JD, Lima LCO, Pasqual M \& Santos VA (2013) Fenologia e características físico-químicas de frutos de abacateiros visando à extração de óleo. Ciência Rural, 43:411418 .

Ramos DP \& Sampaio (2008) AC Principais variedades de abacateiro In: Leonel S \& Sampaio AC (Eds.) Abacate: Aspectos técnicos da produção. São Paulo, Cultura Acadêmica Editora. p.37-64.

Tango JS \& Turatti JM (1992) Óleo de abacate. In: Abacate: cultura, matéria-prima, processamento e aspectos econômicos. Campinas, ITAL. p.156-192.

Tango JS, Carvalho CRL \& Soares NB (2004) Caracterização física e química de frutos de abacate visando a seu potencial para extração de óleo. Revista Brasileira de Fruticultura, 26:17-23.

Teixeira CG (1991) Cultura. In: Teixeira CG, Bleinroth EW, Castro JV, Martin Z, Tango JS, Turatti JM, Leite RASSF \& Garcia AEB (Eds.) Abacate: cultura, matéria prima, processamento e aspectos econômicos. $2^{a}$ ed. Campinas, ITAL. p. 01-57. 